\title{
GRUPO DE PESQUISA GÊNEROS POÉTICOS NA GRÉCIA ANTIGA: TRADIÇÃO E CONTEXTO: APRESENTAÇÃO E UM ESTUDO DE CASO NA ODISSEIA ${ }^{1}$
}

\author{
Christian Werner* \\ Recebido em: 01/07/2019 \\ Aprovado em: 23/07/2019 \\ RESEARCH GROUP POETIC GENRES IN \\ ANCIENT GREECE: TRADITION AND CONTEXT: \\ OVERVIEW AND A CASE STUDY IN THE ODYSSEY
}

* Professor Livredocente de língua e literatura grega, Universidade de São Paulo. Bolsista de Produtividade em Pesquisa, CNPq. crwerner@usp.br $\longrightarrow$ paradigma que tem predominado em reconstruções da história da poesia grega arcaica e clássica confere primazia a contextos de performance e reperformance para se estabelecerem condições de produção e recepção dessa poesia. Com o intuito de investigar essas condições e, em especial, até que ponto faz sentido manter-se alguma noção de gênero em sua descrição, criou-se, na Universidade de São Paulo, o grupo de pesquisa Gêneros poéticos na Grécia antiga: tradição e contexto em 2010. ${ }^{2}$ Embora o objeto de pesquisa principal da maioria de seus membros pesquisadores seja a poesia hexamétrica, também se discute o contexto maior, sincrônico e diacrônico, da cultura musical grega, de sua teorização cada vez mais técnica a partir do século $\mathrm{V}$ a.C. e de sua recepção antiga e moderna. ${ }^{3}$

\footnotetext{
${ }^{1} \mathrm{O}$ presente trabalho foi realizado com apoio do $\mathrm{CNPq}$, Conselho Nacional de Desenvolvimento Científico e Tecnológico - Brasil (304241/2017-2). Uma primeira versão deste texto foi apresentada no I Seminário dos Grupos de Estudo da Sociedade Brasileira de Estudos Clássicos; para essa apresentação, $\mathrm{o}$ autor contou com um auxílio à participação em evento, processo $\mathrm{n}^{\circ}$ 2018/22730-4, Fundação de Amparo à Pesquisa do Estado de São Paulo (FAPESP).

${ }^{2} \mathrm{O}$ grupo, cadastrado no $\mathrm{CNPq}$, tem como líderes Christian Werner e Fernando Rodrigues Junior. O site do grupo é https://generospoeticos. wordpress.com/.

${ }^{3}$ Cf. Werner (2014) e Rodrigues Jr. (2016).
} 
Isso é evidenciado pelos três colóquios organizados pelo grupo: "Gêneros poéticos na Grécia antiga: fronteiras e confluências" (2013), "Tecendo narrativas: unidade e episódio" (2014) e "A Ilíada de Homero e sua recepção na Antiguidade e modernidade" (2018). Os dois primeiros renderam livros, ${ }^{4}$ e do terceiro, em conjunto com o "II Colóquio Internacional sobre poesia grega arcaica do NEAM/UFMG: poesia hexamétrica" (Belo Horizonte, 2018), um evento casado com o de São Paulo, derivaram dois dossiês publicados na revista Classica em 2019. As três publicações testemunham as vantagens da metodologia defendida pelo grupo, qual seja, a de procurar discutir a poesia grega não apenas a partir de suas próprias condições de produção, mas, ao mesmo tempo e em diálogo, a partir de sua teorização e recepção, tanto por parte dos antigos como dos modernos. Essa também é uma das razões pelas quais o escopo do grupo são gêneros poéticos e não, por exemplo, exclusivamente a poesia hexamétrica: embora nada saibamos de concreto acerca da produção e recepção primeira dos poemas homéricos e hesiódicos canônicos, muito pode ser defendido acerca deles uma vez colocados em contextos maiores, como o da tradição mito-poética e da cultura musical da qual fizeram parte e sua recepção entre poetas e críticos antigos e modernos. ${ }^{5}$

A noção de gênero que circunscreve a proposta do grupo é definida a partir de uma visão da poesia grega como fenômeno, em primeiro lugar, social. Nesse sentido, "gêneros poéticos" e "gêneros de discurso", como em outras sociedades tradicionais, compartilham elementos definidores. Os dois principais são o domínio da arte verbal e a interrelação entre um gênero e sua ocasião de performance. Vejamos um exemplo na poesia hexamétrica homérica. ${ }^{6}$

\section{Práticas discursivas e a Cultura do simpósio na POEsia homérica}

A voz de Homero ou, em chave narratológica, o narrador do poema (a partir daqui, irei me referir a essa voz apenas como "Homero", que, portanto, não identifica o autor histórico dos poemas) não nomeia ou define seu canto, explicitamente, como uma forma poética distinta de outras formas. Entretanto, ele e suas personagens distinguem diversas formas de discurso ao longo dos dois poemas, e pelo menos um discurso se aproxima tanto do discurso do próprio Homero que quase se iguala a ele: a narrativa que Odisseu faz de suas aventuras diante dos feácios. Outro discurso significativo é a resposta de Aquiles dada a Odisseu no canto 9 da Ilíada, quando este tenta convencer aquele a se engajar de novo na batalha. ${ }^{7}$ Essas passagens exemplificam que um exame dos discursos da Iliada e da Odisseia, bem como da matriz genérica subjacente a eles, pode nos fornecer pistas acerca das marcas genéricas do próprio discurso poético que os contém: a performance desses discursos reflete e refrata a performance dos próprios poemas.

\footnotetext{
${ }^{4}$ Cf. Werner; Sebastiani; Dourado-Lopes (2014) e Werner; Dourado-Lopes; Werner (2015).

${ }^{5}$ Cf. Werner (2009) e (2012), Duarte (2012), Dourado-Lopes (2016), Zanon (2018) e Frade (2018).

${ }^{6}$ Desenvolvi essas noções em Werner (2018).

${ }^{7}$ Cf. Martin (1989).
} 
Um elemento genérico relacionado aos discursos poéticos arcaicos diz respeito ao simpósio como contexto por excelência da performance de poesia, em particular, da poesia elegíaca e jâmbica. Quanto à poesia hexamétrica, durante muito tempo, a opinião preponderante entre os críticos foi a de que os poemas homéricos não fariam menção alguma a essa instituição aristocrática, que só teria se desenvolvido em época posterior à composição da Ilíada e da Odisseia. Nas últimas décadas, porém, inúmeros argumentos modalizaram ou relativizaram essa visão. Para meus propósitos basta mencionar a conclusão principal de Marek Węcowski segundo a qual o dais, o banquete dito heroico representado na Ilíada e na Odisseia, de forma consistente se diferencia dos banquetes de outros grupos de personagens que não são os guerreiros-heróis em sentido estrito, quais sejam, os deuses (na Ilíada) e os feácios e pretendentes (na Odisseia). ${ }^{8}$ As reuniões promovidas por esses grupos, em graus e formas diversos, se aproximariam dos simpósios aristocráticos. Eu acrescentaria, na esteira de Elizabeth Irwin, que inclusive os banquetes heroicos poderiam conter referências aos simpósios históricos ou, mesmo sem referências mais ou menos explícitas, ser aproximados deles pelo receptor contemporâneo. ${ }^{9}$ Isso é mais evidente sobretudo em performances discursivas que, nos poemas homéricos, se dão em um contexto de banquete ou o mencionam, sobretudo caso se leve em conta o ambiente entre cooperativo e agônico típico dos simpósios, o que se poderia demonstrar ser o caso nas duas cenas mencionadas anteriormente, a recepção dos embaixadores por Aquiles e a narração das aventuras de Odisseu diante dos feácios.

Assim, no canto 9 da Ilíada, quando Odisseu inicia seu discurso formal diante de Aquiles, ele indica que a refeição que lhe é oferecida não lhe interessa, pois idêntica honra recebera de Agamêmnon; seu foco é a troca de discursos. Ao passo que o banquete heroico por si só tende a ser uma ocasião social e religiosa (não apenas porque todo banquete deveria conter também um sacrifício) que reafirma os aristoi como homens superiores, os discursos que nele ocorrem podem revelar diferenças e alianças em processo de (re)negociação no e por meio do discurso, o que de fato ocorre nesse canto.

Węcowski apresenta desta forma as características do banquete heroico homérico em sentido estrito que o diferenciariam de um simpósio: "não temos um banquete noturno, uma divisão entre jantar e beber, consumo de álcool em grande escala com todas as suas consequências naturais, mulheres e erotismo, igualdade, competição e performances por parte dos convivas". ${ }^{10}$ Todos esses elementos, porém, estão presentes, em graus e formas variados, nos banquetes dos outros grupos mencionados anteriormente, sobretudo na Odisseia. No restante deste texto, vou me deter em um desses elementos, o da competição, e mostrar de que maneira, como elemento de um simpósio aristocrático, ele aponta para relações entre a poesia épica e o discurso jâmbico. ${ }^{11}$

\footnotetext{
${ }^{8}$ Cf. Węcowski (2014); Werner (2018) discute algumas cenas “simpóticas” na Odisseia.

${ }^{9}$ Cf. Irwin (2005a); Irwin (2005b) defende o simpósio como contexto de performance do Catálogo das mulheres hesiódico.

${ }^{10}$ Węcowski (2014, p. 214).

${ }^{11}$ Considero que uma noção mínima de "discurso jâmbico" é comum a (quase) todas as tentativas de se diferenciar a poesia jâmbica (independente de seu nome) no período arcaico; para um resumo
} 


\section{Poesia épica heroica e discurso JÂMbico}

Meu ponto de partida é uma passagem no canto 18 da Odisseia, que se inicia por uma disputa, aquela entre o Cretense/Odisseu e o mendigo Iro. Deborah Steiner (2009) demonstrou que essa disputa reflete não apenas diversos tópicos do simpósio, mas também, de forma particular, do gênero ou discurso jâmbico. Na sequência do canto, Penélope aparece diante dos pretendentes, algo raro e eroticamente carregado, e então o Cretense é novamente assediado e intimidado pelos pretendentes. O discurso jâmbico é então mais uma vez evocado desta forma (Od. 18.346-55):

Atena de modo algum deixou os arrogantes pretendentes reprimirem-se no opróbrio (lōbè) aflitivo, para, ainda mais, a angústia entrar no coração de Odisseu, filho de Laerte. Entre eles Eurímaco, filho de Polibo, começou a falar, provocando (kertomeōn) Odisseu; e riso nos companheiros gerou: 350 "Ouvi-me, pretendentes da esplêndida senhora, vou falar o que o ânimo me ordena no peito.

Não sem um deus chegou este homem à casa de Odisseu; parece-me, de todo, que a fulgência das tochas é dele, da sua cabeça, pois nela não há cabelo, nem pouco". ${ }^{12}$

Como "opróbrio" (lōbè, 347) vem logo antes da indicação de que o receptor vai ouvir uma piada construída às custas do Cretense (350), o sentido do termo retroativamente aponta para situações nas quais alguém é ridicularizado verbalmente para gerar riso. ${ }^{13} \mathrm{De}$ fato, kertomeōn (350) sugere gênero de discurso cujo sentido é difícil de precisar, e também implica calúnia e abuso. ${ }^{14}$

Gottesman (2008) demonstrou que, no contexto da poesia hexamétrica, a kertomia ${ }^{15}$ evoca um gênero de discurso praticado por jovens reunidos no simpósio. Trata-se de uma brincadeira combinada com agressão em que o falante assume uma autoridade obliquamente. Nesse sentido, opõe-se ao próprio discurso épico, que, por definição, tem sua origem na Musa e representa as ações memoráveis da linhagem dos heróis. A kertomia, por sua vez, envolve jactância e insulto, elementos típicos do discurso jâmbico e cuja presença na dicção épica é, no máximo, secundária.

Um exemplo de kertomia na Odisseia que também se dá em um ambiente com elementos que poderiam evocar a atmosfera do simpósio é a disputa discursiva entre Odisseu e Domapovo (Laodamas) durante os jogos feácios. Para Gottesman (2008, p. 6), trata-se de

\footnotetext{
dessa difícil discussão, cf. Carey (2009, p. 149-51).

${ }^{12}$ Todas as traduções da Odisseia são de Werner (HOMERO, trad. de Christian Werner, 2018).

${ }^{13}$ Cf. Steiner (2010, p. 208-9).

${ }^{14}$ Steiner (2010, p. 209).

${ }^{15}$ Em Homero, além do substantivo, encontramos também o adjetivo e, com mais frequência, o verbo cognatos.
} 
kertomia pura, pois os jovens proclamam seu status obliquamente. Esta é a reação de Odisseu à provação sofrida $(O d .8 .152-58)$ :

"Domapovo, por que isso me impondes, melindrando-me (kertomeontes)?
Agruras há em meu juízo bem mais que provas,
eu que antes muito sofri e muito aguentei,
e agora, em vossa assembleia, precisando retornar,
estou sentado, suplicando ao rei e a todo o povo".
E a ele Amplomar respondeu e provocou-o de frente (neikese t'antēn)... ${ }^{16}$

Assim, segundo Gottesman, as características pragmáticas da kertomia são as seguintes: ela é indireta (o alvo é um, mas o receptor é outro); é típica de homens jovens em festas; envolve proclamação de status, do próprio e do outro; pode ser afetiva ou agressiva.

Voltando à forma como Homero introduz o discurso do pretendente Eurímaco no canto 18, a informação de que "riso nos companheiros gerou" (350) torna ainda mais preciso o gênero discursivo em questão. ${ }^{17} \mathrm{O}$ membro do grupo procura sedimentar sua liderança por meio de uma performance verbal; o riso é um sinal de que é bem-sucedido.

Após a kertomia (351-55), Eurímaco dirige-se ao Cretense (356-64), e seu tom parece mudar, pois lhe oferece trabalho. O texto, porém, cria uma tensão por meio do epíteto que Homero utiliza para Odisseu no verso que anuncia o discurso: "Falou e nisso dirigiu-se a Odisseu arrasa-urbe (ptoliporthos)". A falsa boa intenção não só está em tensão com o epíteto marcial, mas fica explícita com a censura que encerra o discurso, pois o Cretense é representado como um escravo do seu estômago, ${ }^{18}$ um tema jâmbico.

Odisseu assim reage ao insulto (Od.18.366-80):

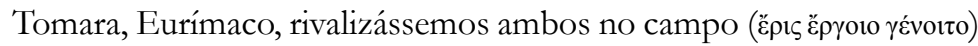
durante a primavera, quando os dias são longos,

no pasto: foice eu teria, boa-curva,

e tu também isso terias para no campo nos testarmos,

jejuando (nèstis) até a escuridão total, e pasto haveria!

Se bois também houvesse para conduzir, os melhores, ardentes, enormes, ambos saciados de pasto,

mesma idade, tração igual, boa força, seriam quatro medidas, e o torrão cederia sob o arado:

assim me verias, se os sulcos, de uma só vez, não cortaria.

Se guerra também, de um lado, o filho de Crono instigasse

hoje, e para mim houvesse um escudo, duas lanças

e um elmo todo de bronze ajustado nas têmporas, assim me verias unindo-me aos primeiros na vanguarda,

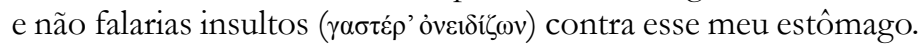

\footnotetext{
${ }^{16}$ Tradução com modificações.

${ }^{17} \mathrm{Na}$ Ilíada e na Odisseia são bastante raros os discursos cujo objetivo explícito é provocar riso.

${ }^{18} \mathrm{Od}$. 362-64: "Mas sim, como aprendeste serviços vis, não quererás / fazer o serviço, mas curvar-se pelas redondezas / preferes, para poder engordar teu estômago insaciável”.
} 
Trata-se de um discurso extraordinário sob diversos aspectos. Ao insistir que poderia laborar no campo o dia inteiro sem comer, Odisseu reage ao insulto de que teria um “estômago insaciável” (gaster' analton, 364). Analtos é um adjetivo cujo uso supérstite praticamente se restringe à Odisseia, poema no qual aparece três vezes nos cantos 17 e 18 , sempre ligado ao papel do Cretense como mendigo. ${ }^{19}$ De fato, o papel temático do estômago nesse poema levou Pietro Pucci (1995) a defender que a Odisseia seria definida por uma poética do gastèr.

O Cretense proclama seu valor desde o primeiro verso desse discurso propondo

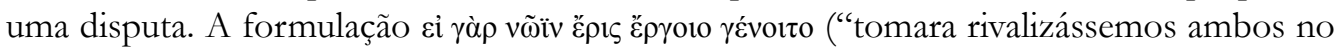
campo", 366) deixa explícito que ele considera Eurímaco, socialmente, seu igual. ${ }^{20}$ São três as modalidades de provas que propõe (366-86), todas envolvendo, direta ou indiretamente, a alimentação: colheita em jejum; lavra (menciona-se o alimento dos bois); combate guerreiro (o desempenho do Cretense silenciaria o deboche de Eurímaco contra seu estômago).

A última palavra, portanto, é a de um Odisseu épico, e não jâmbico (376-86). Odisseu já havia sido caracterizado por Homero como "arrasa-urbe”, ou seja, seu discurso de desafio não sugere, de fato, um paralelo entre a atividade agrícola, de paz, e a guerreira. Quem o receptor do poema ouve nesse momento é Odisseu como o herói que, segundo a tradição, mata os pretendentes de Penélope. Assim como Odisseu desafia os jovens feácios, seu discurso a Eurímaco revela que ele nunca abandona seu papel tradicional, aquele de guerreiro épico. Em contraste com a performance em tom jâmbico de Eurímaco, o vetor épico-heroico é reiterado no discurso de Odisseu. Por outro lado, a Odisseia se diferencia de

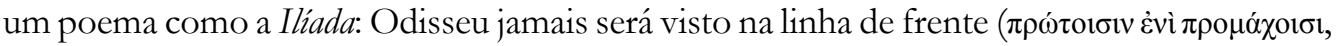
379), pelo menos não no sentido iliádico. A batalha contra os pretendentes será conduzida dentro desse mesmo salão, e os principais pretendentes serão derrotados "de longe", ou

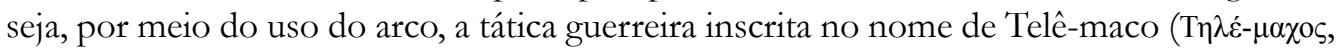
"combater de longe").

\section{Simpósio E RIVALIDADE EM ArQuíloco 172-81 W}

Vejamos agora, brevemente, como essa mesma constelação temática aparece nos fragmentos de um epodo da figura jâmbica por excelência, Arquíloco: o ainos da águia e da raposa (Arquíloco 172-81 W). De acordo com a reconstrução moderna do poema, trata-se de uma invectiva do eu lírico contra Licambes, a qual, por sua vez, produz o pano de fundo para a narração de uma fábula (Arquíloco 172): ${ }^{21}$

Pai Licambes, que é isso que pensaste?

Quem virou teu juízo, no qual no passado te escoravas? Agora como grande

\footnotetext{
${ }^{19}$ Além da passagem citada, Od. 17.228 e 18.114.

${ }^{20}$ Cf. Steiner (2010, p. 212).

${ }^{21}$ Minha tradução de Arquíloco a partir de West (1989).
} 
motivo de riso apareces aos cidadãos.

$\mathrm{Na}$ fábula, a águia e a raposa fazem um acordo a respeito dos respectivos filhotes. Quando a águia o rompe e devora os filhotes da raposa, esta põe em andamento algum tipo de vingança por meio da intercessão divina, e aquela, ao tentar, um dia, alimentar seus filhotes com o pedaço de carne de um sacrifício, sem querer traz junto algumas fagulhas que acabam por incendiar seu ninho, fazendo os filhotes caírem e serem devorados pela raposa.

$\mathrm{Na}$ invectiva contra Licambes, é possível que, de alguma forma, fosse desenvolvido o tema da hospitalidade ou comensalidade, mesmo que de uma forma metonímica, qual seja, por meio do acordo, acompanhado de juramento, entre os dois cidadãos acerca do casamento da filha de Licambes com Arquíloco. Um trecho do epodo é citado por Orígenes em Contra Celsum 2.21:

Quem não sabe que muitos que compartilharam o sal e a mesa conspiraram contra seus companheiros de banquete? A história dos gregos e bárbaros está cheia de tais exemplos. De fato, é a censura que o poeta jâmbico de Paros dirige contra Licambes por ter quebrado um acordo 'pelo sal e pela mesa': 'Tu rejeitaste o grande juramento ${ }^{22}$ pelo sal e pela mesa'. (Arquíloco $173 \mathrm{~W}$ ).

A mesa compartilhada vale, metonimicamente, para os laços de aliança, de amizade entre dois homens, e é uma tal união o mote inicial da fábula (Arquíloco $174 \mathrm{~W}$ ):

Essa é uma fábula dos homens, como a raposa e a águia em amizade se uniram...

A águia, porém, provavelmente por confiar em sua qualidade física superior, pois, por saber voar, tem acesso a um espaço vedado à raposa, quebra o acordo. No fragmento $176 \mathrm{~W}$, menciona-se um deboche, possivelmente um discurso de jactância da águia (Arquíloco 176 W):

Vês onde aquela montanha é altíssima, escarpada e hostil?

Nela está sentada(-o?), menosprezando teu combate.

Não é possível identificarmos quem está envolvido nessa fala, mas, em algum momento, a raposa dirige uma prece a Zeus (Arquíloco $177 \mathrm{~W}$ ):

Ó Zeus, pai Zeus, teu é o poder sobre o céu, tu vês os feitos dos homens, criminosos e lícitos, e das feras a desmedida e a justiça te ocupam.

\footnotetext{
22 Acerca do sentido de "grande juramento", cf. Gagné (2009, p. 252): “a powerful symbol of community and justice, the oath functions as a multi-layered node of meaning in the poem".
} 
Como no discurso do Cretense contra Eurímaco, no qual também é identificada a bubris do adversário, ${ }^{23}$ aquele que parece ser mais fraco (a raposa e o Cretense) pode confiar na palavra, ou melhor, em um certo ato de fala: em Arquíloco, uma prece, ${ }^{24} \mathrm{e}$ no discurso do Cretense, por um lado, um desafio que não será atendido (Odisseu não voltará a lutar na linha de frente como em Troia), mas, por outro, uma coda jactante que funciona como previsão, sua própria vingança no espaço exíguo do megaron. ${ }^{25}$

Por fim, o tema do gastèr também tem lugar central na fábula de Arquíloco, em particular por essa ser permeada por refeições impróprias ou conspurcadas. Vale notar que, caso o poema fosse apresentado em um ambiente simpótico, no qual se negociam e/ou se atualizam laços entre aristocratas, a dimensão do gastêr seria potencializada, tendo em vista os acordos "em torno da mesa" dos quais participam, de um lado, Arquíloco e Licambes, e, de outro, a águia e a raposa. ${ }^{26}$

\section{ConClusão}

Os discursos examinados, sob a perspectiva da performance, tanto no jambo como na poesia épica, revelam formas de se firmar autoridade por meio da atualização de determinados gêneros discursivos $e$ poéticos. Isso é potencializado pela forma como os gêneros poéticos poderiam evocar-se mutuamente, sobretudo por intermédio de seus contextos de performance, fossem eles distintos ou não. Assim, a kertomia de Eurímaco mostra-o tentando firmar sua autoridade em relação aos outros pretendentes, o que confere ainda mais destaque ao desafio (eris) proposto por Odisseu, uma disputa de tal forma direta que o coloca no mesmo nível social de Eurímaco, o que só pode deixar seu adversário furioso (387) e sem resposta verbal. Como resultado, na cena simposial odisseica, também marcada pela disputa como no ainos de Arquíloco, o discurso vitorioso é o épico, mas um épico em sua vertente "odisseica", a qual é produzida justamente pela aproximação genérica com o discurso jâmbico graças à utilização do imaginário do simpósio. ${ }^{27}$

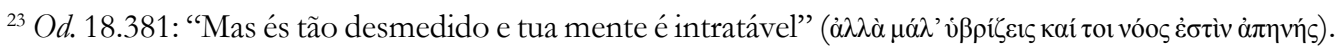

${ }^{24}$ Acerca da imprecação contra a águia como único modo de defesa, cf. Gagné (2009, p. 256), que nota que, em Esopo, "it points towards the unequal power dynamics between the two animals, and the ultimate triumph of divine justice over raw power".

${ }^{25}$ Od. 18.384-86: "Se Odisseu voltasse e alcançasse sua terra pátria, / logo para ti essas portas, embora muito largas, / seriam estreitas ao tentares fugir pórtico afora”.

${ }^{26}$ Cf. Gagné (2009, p. 266): "in the ainos, the entire narrative is framed in terms of eating, a fascinating activation of the sympotic context of performance in the narrative logic of the tale's warning".

${ }^{27}$ Acerca do cenário simposial em diversas cenas com os pretendentes na Odisseia, diz Węcowski (2014, p. 232): "some verbal performances of the Suitors belong to the 'meta-sympotic discourse' that characterizes the sympotic literature from the 'Cup of Nestor' onwards... It is also noteworthy that all these remarks and speeches by the Suitors are not only aggressive - they are competitive. At times, their victims strike back and respond to the Suitors in the same vein". De fato, na nota 388, nessa mesma página, o autor cita como exemplo justamente $\mathrm{Od}$. 18.366-86.
} 
Assim, não foi por acaso que Oswyn Murray (2008), em uma ousada tentativa de propor um contexto específico de performance da Odisseia, defendeu que o poema, praticamente construído como uma sequência de cenas de hospitalidade, tenha sido composto para ser apresentado em uma sucessão de mais ou menos 40 banquetes diários, vespertinos, em um ambiente aristocrático. Se non è vero è ben trovato.

\section{REFERÊNCIAS}

CAREY, Chris. Iambos. In: BUDELMANN, F. (Org.). Cambridge companion to Greek lyric. Cambridge: Cambridge University Press, 2009, p. 149-67.

DOURADO-LOPES, Antonio Orlando. A destruição do muro aqueu no canto XII da Ilíada: questões e interpretações. Classica, v. 29, n. 1, p. 233-272, 2016.

DUARTE, Adriane da Silva. Cenas de reconhecimento na poesia grega. Campinas: Ed. Unicamp, 2012.

ESOPO. Fábulas completas. Tradução de Maria Celeste Consolin Dezotti. Apresentação: Adriane da Silva Duarte. São Paulo: Cosac Naify, 2013.

FRADE, Gustavo. Poesia, profecia e a experiência do divino na Grécia Antiga. Nuntius Antiquus, v. 14, p. 187-206, 2018. DOI: http:/ /dx.doi.org/10.17851/1983-3636.14.1.187-206

GAGNÉ, Renaud. A wolf at the table: sympotic perjury in Archilochus. Transactions and Proceedings of the American Philological Association, v. 139, p. 251-74, 2009.

GOT'TESMAN, Alex. The pragmatics of Homeric kertomia. Classical Quarterly, v. 58, p. 1-12, 2008.

HOMERO. Odisseia. Tradução de Christian Werner. São Paulo: Ubu, 2018.

IRWIN, Elizabeth. Solon and early Greek poetry. The politics of exhortation. Cambridge: Cambridge University Press, 2005a.

IRWIN, Elizabeth. Gods among men? The social and political dynamics of the Hesiodic Catalogue of women. In: HUNTER, Richard (Org.). The Hesiodic Catalogue of women. Cambridge: Cambridge University Press, 2005b, p. 35-84.

MARTIN, Richard P. The language of heroes. Speech and performance in the Iliad. Ithaca: Cornell University Press, 1989.

MURRAY, Oswyn. The Odyssey as performance poetry. In: REVERMANN, Martin; WILSON, Peter (Org.). Performance, iconography, reception. Studies in honour of Oliver Taplin. Oxford: Oxford University Press, 2008.

NAGY, Gregory. The best of the Achaeans. Concepts of the hero in archaic Greek poetry. 2nd ed. Baltimore: Johns Hopkins University Press, 1999. 
PUCCI, Pietro. Odysseuspolutropos. Intertextual readings in the Odyssey and the Iliad. Ithaca: Cornell University Press, 1995.

RODRIGUES JR., Fernando. Os mimos populares e os espetáculos dramáticos no período helenístico. PhaoS: Revista de Estudos Clássicos, v. 15, p. 49-64, 2015.

STEINER, Deborah. Diverting demons: ritual, poetic mockery and the Odysseus-Iros encounter. Classical Antiquity, v. 28, p. 71-100, 2009.

STEINER, Deborah. Homer. Odyssey, Books XVII and XVIII. Cambridge: Cambridge University Press, 2010.

WECOWSKI, Marek. The rise of the Greek aristocratic banquet. Oxford: Oxford University Press, 2014.

WERNER, Christian. Reputação e presságio na assembleia homérica: poluphemos em Odisseia 2, 150. PhaoS: Revista de Estudos Clássicos, v. 9, p. 29-52, 2009.

WERNER, Christian. Afamada estória: 'Famigerado' (Primeiras estórias) e o canto IX da Odisseia. Nuntius Antiquus, v. 8, n. 1, p. 29-50, 2012. DOI: http://dx.doi.org/10.17851/19833636.8.1.29-50

WERNER, Christian. Lágrimas em verso: o canto crítico em Aristófanes e Eurípides. In: JUNQUEIRA, Renata; VICENTE, Adalberto L. (Org.). Teatro, cinema e literatura: confluências. São Paulo: Cultura acadêmica/Ed. Unesp, 2014, p. 177-200.

WERNER, Christian. Memórias da Guerra de Troia. A performance do passado épico na Odisseia de Homero. Coimbra: Imprensa da Universidade de Coimbra, 2018. DOI: https://doi. org/10.14195/978-989-26-1502-8

WERNER, Christian; SEBASTIANI, Breno; DOURADO-LOPES, Antonio Orlando (Org.). Gênerospoéticos na Grécia Antiga: fronteiras e confluências. São Paulo: Humanitas/CNPq, 2014.

WERNER, Christian; DOURADO-LOPES, Antonio Orlando; WERNER, Erika (Org.). Tecendo narrativas. Unidade e episódio na literatura grega antiga. São Paulo: Humanitas/CNPq, 2015.

WEST, M. L. Iambi et elegi graeci ante Alexandrum cantati. 2nd ed. Oxford: Clarendon, 1989.

ZANON, Camila A. Onde vivem os monstros: criaturas prodigiosas na poesia de Homero e Hesíodo. São Paulo: Humanitas/Fapesp, 2018. 